LUXIÉRNAGA

Hillary Loza Cuellar 


\section{Un Knock out social}

\section{Introducción}

Todo ahora es diferente, la vida ha cambiado de manera inminente y casi sin que nos demos cuenta de ello. Se ha dejado de lado la importancia de tantas cosas, al parecer vivimos en una clase de "modo automático", ya no surgen preguntas filosóficas, ya no hay interés en el porqué de las cosas, no hay curiosidad dentro de nosotros; ¿Qué está pasándole a la sociedad?, acaso es que hemos perdido una parte de ser humano que jamás volverá, la sensibilidad, el deseo de vivir, la felicidad, la importancia del cuerpo, del arte, la cultura, el amor, el conocimiento, la vocación, ¿todo esto ya ha sido reemplazado? creemos que sí.

Avanzamos a zancadas enormes, la vida está corriendo muy aprisa, la ciencia y la tecnología parecen encerrarnos en una burbuja invisible, de la cual es imposible escapar, todos y cada uno de nosotros estamos dentro de ella.

Las nuevas tecnologías nos han transformado en lo que Guy Deboard llama 'La sociedad del espectáculo' y que más adelante Mario Vargas Llosa vuelve a retomar en 'la civilización del espectáculo'; las redes sociales han generado en nosotros actitudes de desinterés, pérdida de identidad, nos hemos convertido, claramente, en una sociedad en la que se premia a los mejores civiles en base al éxito que tienen en sus redes, la influencia que tienen ante los demás; hemos perdido la importancia de la intelectualidad, los saberes contenidos en nosotros, ya no almacenamos nada, todo se ha vuelto desechable, y tal parece que vivimos en una sociedad desechable también, que no se preocupa por valorar, cuidar, recompensar las buena acciones; se premia a un futbolista de la misma manera que se premia a un intelectual del premio nobel, y esto claramente es indignante. 
En el presente trabajo pretendemos dar a conocer, ampliar y relacionar la 'civilización' del espectáculo y la 'sociedad' del espectáculo en las redes sociales, y cómo esto, sin duda, genera en nosotros conflictos, tanto individuales como colectivos.

"Las horas han perdido su reloj".

-Vicente Huidobro.

\section{Un knock out ${ }^{\mathrm{I}}$ social.}

A lo largo de la historia de la humanidad se han vivido diversas transformaciones en nuestra forma de ser, de ver el mundo, de comunicarnos y de interactuar con los demás; se ha transformado nuestra visión de las cosas gracias al surgimiento de las tecnologías, la importancia de que el hombre haya encontrado un método para mejorar su estilo de vida, las creaciones tecnológicas y científicas que han revolucionado a lo largo de la historia nuestra forma de ser, de trabajar y de pensar ahora parecen no ser tomadas como lo que son.

Desde que el 'Homo tecnologicus', en la era de la prehistoria, trabajó por su supervivencia como especie, se ha demostrado que la raza humana tiene algo más que ingenio para llevar a su vida y a la cotidianidad lo mejor de la naturaleza, apropiándose en primera instancia del fuego como suyo, creando lanzas para cazar sus presas, vestimentas con piel de animales, el lenguaje con señales de humo, artefactos musicales, etc. ¡eso también es tecnología!, tal vez ahora no se compara a ese móvil nuevo que puedes sostener y con un dedo manejar, ni al automóvil que conduces, sin problema, con el fresco aire acondicionado en su interior, pero en un inicio esto también fue tecnología.

Algunos de los principales indicios tecnológicos más antiguos que conocemos son las herramientas de trabajo que serán aproximadamente de hace más de 3.4 millones de años, el fuego hace un millón de años, el pan en el 30000 a.C. en Europa, la cerámica

\footnotetext{
${ }^{1}$ Dejar sin conocimiento. http://www.wordreference.com/definicion/knock\%20out
} 
hace 20000 años en china, la rueda en el 3500 a.C. en Mesopotamia, o las figuras geométricas en 2700 a.C. en Egipto; ${ }^{2}$ esto por mencionar algunas de las herramientas más antiguas, y consideradas, como las más relevantes.

Desde hace ya algunas décadas la sociedad empezó a crear una red global de información, en la que se han modificado las ideas o formas de pensar, juicios de valor tanto científicos como de arte, de educación, comercio, política, religión, moda, lenguaje, entre otras cosas. Muchas de estas transformaciones, a la sociedad le han sido benéficas, como en cuestiones médicas y farmacológicas, incluso en el aspecto industrial, comunicativo, y más; pero también ha traído consigo problemáticas sociales, ambientales, e individuales que son ahora imposibles de erradicar.

La internet nos lleva a una de las plataformas más usadas de hoy en día, las cuales surgieron como una forma de cubrir la necesidad de la comunicación entre la sociedad, y así surgieron las redes sociales como: Facebook, Twitter, Instagram, Correo electrónico como Hot mail, G-mail, etc., WhatsApp que, han traído a nosotros una nueva forma de estar conectados con los demás; las conversaciones, temas de interés, lo más relevante de la moda, lo más gracioso de la semana, todo lo que se pueda imaginar, está dentro de esas plataformas.

Las redes sociales, como las mencionadas anteriormente, permiten al usuario generar un perfil con sus datos, y para ello ofrecen al usuario completar el mayor número de datos posibles: nombre, edad, sexo, foto, aficiones y gustos, formación académica, profesión e incluso orientación sexual, de modo que toda ésta información se hace pública para todos los demás usuarios ya que por defecto, la accesibilidad del perfil no es sólo para tus amigos, sino también para las personas que forman parte de la lista de contacto, de tus amigos.

¿Cómo es posible que esto nos genere conflictos sociales? existe un problema derivado de la falta de toma de conciencia real por parte de los usuarios de que sus datos

\footnotetext{
${ }^{2}$ Cfr. Aguilera, C. (2018). “Los 100 inventos más importantes de la historia”, en Muy interesante Historia, No 72. Noviembre. p. 62.
} 
personales serán accesibles por cualquier persona. Se desconoce, en gran medida, que los perfiles pueden ser archivados, facilitando la creación de bases de datos de personas con fines ilícitos. Y tras la creación de las redes sociales y la ampliación excesiva de usuarios que ingresan, día con día, a estas plataformas, el impacto de riesgo aumenta, las medidas de seguridad y de privacidad se han transformado asiendo que cada día más personas, menores de edad y adolescentes en su mayoría, tengan acceso con mayor facilidad a cualquiera de estos sitios.

Otro conflicto común en las redes sociales es el caso del cyberbullyng en el cual se desarrollan conductas hostiles, se ataca la reputación, se daña la intimidad a través de comentarios, se inventan historias, se crean perfiles falsos, se hace suplantación de la personalidad, se etiquetan fotos, se insulta, se amenaza y se chantajea con subir fotografías para exhibir a otras personas, etc.

En definitiva, lo hasta aquí expuesto contribuye a una revolución de la información, ya que cada vez dependemos más de él y sobre todo si es un fenómeno que irá creciendo. Con Internet, lo que conseguimos son motores de conocimiento, con ello, conseguimos mover información que antes no podíamos mover, y en esto consiste la nueva revolución, pero, por otra parte, en lo que mencionamos sobre los conflictos de red se debe de tener mayor precaución.

La sociedad ha hecho de estas herramientas sus armas de poder y abuso, lo que genera conflictos a menor y mayor escala, desde el surgimiento de estas redes también se ha generado 'una' civilización del espectáculo, en donde "el primer lugar en la tabla de valores vigente lo ocupa el entretenimiento". El espectáculo surge como una forma de liberación, diversión, y entretenimiento, individual y colectivo.

Para hablar sobre el espectáculo es importante definir como se entenderá esta: pues es: "todo aquello que es capaz despertar la atención de una importante cantidad de

\footnotetext{
${ }^{3}$ Llosa, M. V. (2015). La civilización del espectaculo. Editorial de Debolsillo. España, p. 40.
} 
gente o actuación que se lleva a cabo en un lugar público con la misión de entretener, divertir, al público que la presencia”.

Hoy en día todo gira alrededor del espectáculo, todo ha sido transformado en algo que 'aparenta lo que no es', la cultura, como uno de los casos más emblemáticos para Mario Vargas Llosa, en la que esta se ha transformado y ha perdido su valor, la calidad, la profundidad y excelencia; pero lo más preocupante, es que se está perdiendo la capacidad crítica que tenía en un principio esa cultura para enfrentarse ante las problemáticas sociales; y ahora ha caído únicamente en la diversión y el entretenimiento para las masas, abaratando todo lo que hay dentro de ella.

Frente a esta postura de Vargas Llosa parece ser que nuestra sociedad ha ido marcando lo que es cultura, lo bueno, lo que vale la pena ver, escuchar, sentir, vestir, etc., con un fin único, y limitado para determinarnos y ser como individuos y en masa como una nueva sociedad.

Guy Debord, un filósofo que también retoma el espectáculo en la sociedad, nos dice que "el espectáculo somete al hombre", 5 y nos habla sobre la degradación que tiene el ser en tener, ésta es una fase actual en la que pensamos que el hecho de tener acumulados objetos, bienes, productos, nos hará lo que somos, cuando la realidad es otra, nuestras pertenencias son algo banal, no definen quienes somos, no definen lo que creemos en realidad, estamos disfrazándonos, día a día, con la idea del consumismo, esa idea sustentada en que debes tener los mayores bienes posible para ser feliz, debes tener belleza, estar a la moda, ir más rápido; pero, se nos ha olvidado lo que en realidad somos, nuestra preocupación por leer un buen libro, disfrutar una buena charla, la importancia del medio ambiente, etc.

El espectáculo también ha modificado nuestra forma de comunicarnos a través de las redes sociales, el lenguaje, que se ha sustituido un sentimiento, una palabra por algo

\footnotetext{
${ }^{4}$ definiciones ABC. (06 de junio de 2018). Obtenido de https://www.definicionabc.com/social/espectaculo.php

${ }^{5}$ Debord, G. (1967). La sociedad del espectaculo. Ediciones Naufragio. París, p. 71.
} 
como un emoji, , $^{6}$ imagen, un GIF, etc. Las redes sociales han sido las principales impulsoras del espectáculo actual, y han surgido con el fin de la "complacencia y la autosatisfacción", 7 la facilitación de todo lo que nos rodea, porque nos hemos vuelto seres incapaces de escribir un párrafo plasmando nuestras ideas, la ortografía, la escritura a mano, etc. Muchas cosas han cambiado desde el surgimiento de las redes sociales, hemos estado buscando únicamente lo más fácil, sin esfuerzo, sin concentración, porque nos guardamos únicamente para la diversión, y ahora llevamos una vida light, sin preocupaciones.

A partir de la sencilla accesibilidad que ahora se tiene a estos medios de comunicación y entretenimiento, nos damos cuenta de que, en la sociedad del siglo XXI, se ha perdido la valoración de lo intelectual; las figuras políticas y religiosas ahora crean propaganda no sólo en radio y televisión, sino que ellos también usan estas redes para manifestar comunicados, atraer a más personas, y parece que esto es lo positivo de las redes; pero qué pasa cuando una figura como un presidente del país usa estos medios con fines de investigación de la vida privada de los demás; o en el caso de la política, cuando usan a artistas renombrados, de cine, YouTube, tv., para engrandecer su campaña política haciéndole creer también a los demás que la política, es un medio de 'espectáculo’, y esto traerá más seguidores a sus campañas políticas, mayor alcance de seguidores en sus redes y mayores votos en las elecciones.

Se ha malinterpretado tanto el uso de estas plataformas de comunicación que ahora nos es difícil pensar un día sin ellas, ingresamos a estos sitios para saber de la vida de los demás, y no de una forma sana, sino como una intromisión; se da una imagen individual en la que no se es auténtico, porque claramente no hablarás de tus defectos, ni te mostrarás como verdaderamente eres, éstas redes surgen como una cortina de humo que sólo deja ver lo que tú quieres que vean los demás de ti; se suben las mejores imágenes, se transmiten las mejores fiestas, creas un estado con las frases más profundas

\footnotetext{
${ }^{6}$ Emoji: es una palabra japonesa que se utiliza para designar las imágenes o pictogramas que son usados para expresar una idea, emoción o sentimiento en medios de comunicación digital.

${ }^{7}$ Llosa, M. V. (2015). Op. Cit, p. 235.
} 
que tal vez no son capaces ni de entender; el espectáculo es llevado a los demás, de tantas y distintas formas, que pareciera que somos parte de él, como él de nosotros.

Una de las preocupaciones que surgen de este modo de vivir reciente, es la pérdida de individualidad e integridad tanto del hombre, como de la mujer, a través de las redes sociales; la individualidad se pierde en el momento que se decide hablar de tu vida privada y transformarla en las redes, a conveniencia de lo que la sociedad cree que es mejor "el individuo se desindividualiza y se vuelve parte de la masa y de manera inconsciente regresa a los tiempos primitivos", 8 se trata de un individuo que intenta encajar ante los demás aunque esto implique perder quienes realmente son para mostrarse ante los demás, como 'debería de ser'.

La 'sociedad' del espectáculo es caracterizada por depender del entretenimiento y, justamente las redes sociales, se han encargado de hacer que todo sea de tal forma, desde los debates presidenciales, que se modifican para crear remix de canciones, imágenes artísticas usadas con fines de diversión y representantes religiosos, también forman parte del juego, figuras intelectuales, el uso de freses filosóficas en fotos de perfil, la mala interpretación del lenguaje, no hay respeto por los derechos de autor, ahora todo es de todos, pero a la vez, esto no refleja más que la vaguedad en la que ha caído todo: economía, cultura, deporte, religión, política, lenguaje, etcétera.

Y al ver todo lo anterior con tanta vaguedad, nos cuestionamos: ¿con qué sentido vemos el mundo? el entretenimiento no nos da conocimiento, lo único que esto representa es el poco sentido que ahora se tiene para apreciar lo verdaderamente relevante; muchas de las cosas que surgen en las redes son para llamar la atención del usuario, se fomentan videos de agresión sexual y física, temas como el machismo y feminismo con sentidos muy distintos, la propaganda de drogas, el uso de sustancias ilícitas, la propagación de violencia animal, asesinatos, pornografía infantil y más, son cosas que aparecen en nuestras plataformas sociales como contenidos de máxima importancia, con un mayor rating.

${ }^{8}$ Ídem, p. 137. 
Lo más visto por la sociedad, tristemente, son esta clase de contenidos que sólo sirven para alimentar la ignorancia de las masas, mantener dormida a la sociedad, fomentar conductas en adolescentes y menores, a base de bombardeos de contenidos transformados y manipulados llenos de negatividad, y apatía, que generan contagio mayormente en los adolescentes y jóvenes.

Se debe de cuidar la privacidad de contenidos, no aptos, para menores de edad y eso sin duda erradicaría muchas de las tendencias a suicidios, machismo, ignorancia tanto en los adolescentes como en jóvenes, pero algo a mayor escala sería la propagación en redes sociales de contenidos que verdaderamente sean relevantes, generen interés tanto en gente joven como en adultos; no se puede erradicar los contenidos que ahora existen en la red, pero lo que se puede hacer es mejorar la calidad de contenidos que tienen mayor alcance y mayor publicidad, por ejemplo en temas científicos, en debates filosóficos, en propagación de libros, en trasmisiones en vivo de actividades deportivas, conferencias intelectuales, entrevistas a científicos, médicos, abogados, filósofos, artistas, que vuelvan a despertar la chispa que estos temas han perdido.

\section{Concusión}

¿Qué pasaría si empezáramos a usar las redes para hacer ruido intelectual en los demás? Proponemos que debemos usar estas plataformas para generar conciencia, hablar sobre temas de interés, el cuidado del cuerpo y la salud, diversidad sexual, los derechos y obligaciones, equidad de género, cuidado ambiental, debemos también buscar el que fomentemos valores como la tolerancia, el respeto, honestidad; el verdadero cambio empezará cuando, individualmente, cambiamos, y generamos un impacto en los demás; cuidemos de nosotros mismos, y cuidemos lo que hacemos circular en las redes, no nos volvamos títeres del espectáculo, cuando seamos quienes radiquen la sociedad del entretenimiento y se vuelva una sociedad culta, intelectual y capaz de afrontar y resolver sus propios conflictos. 